\title{
Boberg-Ans intraocular lenses: a retrospective study
}

\author{
A. D. ATKINS and S. G. HENDELES
}

From the Birmingham and Midland Eye Hospital, Birmingham

SUMMARY A retrospective study of 102 cases of Boberg-Ans intraocular lens implantations was conducted. The operations were performed in 3 Birmingham eye units by 5 consultants and 6 surgeons in training. Follow-up ranged from 6 months to 2 years, with a mean of 12.6 months. No cases with adequate follow-up were excluded. When eyes with pre-existing adverse factors were excluded, $87 \%$ achieved $6 / 12$ or better. There were no appreciable difference between the results obtained by consultants and those of surgeons in training. The advantages and disadvantages of the lens are discussed.

Implant surgery has advanced steadily over the years and is becoming increasingly performed by ophthalmologists other than specialist implant surgeons. Furthermore it is becoming increasingly important that surgeons undergoing higher surgical training are taught safe implant techniques. Some consultants

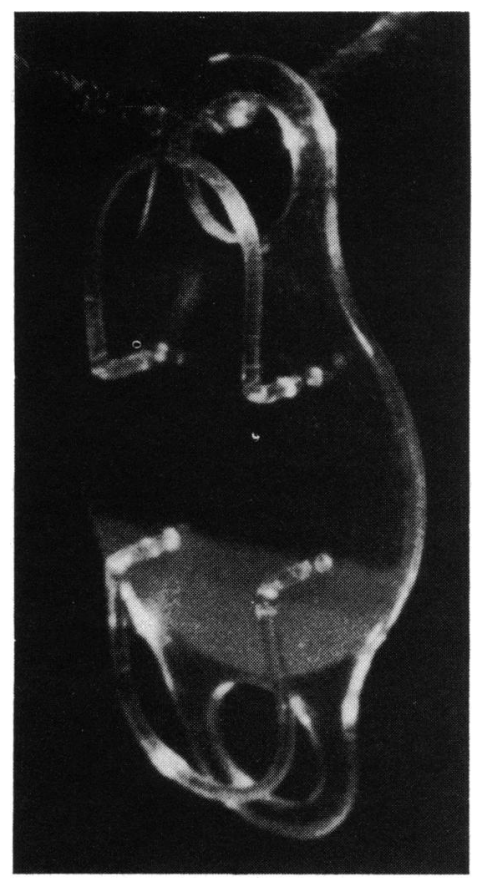

Fig. 1 A Boberg-Ans lens.

Correspondence to Mr A. D. Atkins, FRCS, Birmingham and Midland Eye Hospital, Church Street, Birmingham B3 2NS. involved in teaching junior staff consider that, because of the increased risk to the corneal endothelium during the first few implantations, a posterior chamber intraocular lens has advantages as a 'trainer' lens. Fig. 1 shows a Boberg-Ans lens.

The Boberg-Ans posterior chamber intraocular lens ${ }^{12}$ is gaining popularity. It has the advantage of lying posterior to the iris, protecting the corneal endothelium should the anterior chamber be lost. The purpose of this study was to look at the performance of the Boberg-Ans lens, within the limitations of the follow-up period, in the hands of surgeons in training and several experienced ophthalmic surgeons.

\section{Patients and methods}

The case notes of 102 consecutive intracapsular cataract extractions and Boberg-Ans implants were studied. There were 100 cases-2 had bilateral surgery. The patients came from the Birmingham and Midland Eye Hospital, Selly Oak Hospital, and East Birmingham Hospital. All eyes with a minimum follow-up of 6 months were included.

\section{METHOD OF OPERATION}

A standard intracapsular extraction was performed, usually under general anaesthesia. Alphachymotrypsin and cryoextraction were followed by intraocular lens insertion. Most surgeons preferred to engage the upper loops as a second manoeuvre, working in a closed anterior chamber. Except where specified otherwise, all lenses were sutured to the iris. Postoperative treatment consisted of topical steroid/ antibiotic drops and acetazolomide orally when 
Table 1 Final visual acuities (refracted)

\begin{tabular}{lllllllll}
\hline & $6 / 6$ & $6 / 9$ & $6 / 12$ & $6 / 18$ & $6 / 24$ & $6 / 36$ & $6 / 60$ & $C F$ \\
\hline Cases operated on by consultants & 20 & 16 & 10 & 2 & 2 & 2 & 2 & 2 \\
Cases operated on by surgeons in training & 13 & 12 & 11 & 3 & 1 & 1 & 1 & 4 \\
Total & 33 & 28 & 21 & 5 & 3 & 3 & 3 & 6 \\
\hline
\end{tabular}

$\mathrm{CF}=$ counting fingers.

required. The patients were seen one to 2 weeks after discharge and at intervals after this by regular ophthalmic staff who were not aware that the study was to be undertaken. Visual acuities used in the study were from refractions done by opticians or junior staff in the various clinics.

Table 2 Certain adverse factors not related to surgery or the presence of the intraocular lens

\begin{tabular}{llll}
\hline & Consultants & $\begin{array}{l}\text { Surgeons } \\
\text { in training }\end{array}$ & Total \\
\hline Pre-existing maculopathies & 2 & 5 & 7 \\
$\begin{array}{l}\text { Postoperative trauma requiring } \\
\text { IOL removal and wound repair } \\
\text { Total }\end{array}$ & 1 & 5 & 8 \\
\hline
\end{tabular}

Table 3 Comparison between cases operated on by consultants and by surgeons in training

\begin{tabular}{|c|c|c|c|}
\hline & $\begin{array}{l}\text { Eyes achieving } \\
6 / 12 \text { or better }\end{array}$ & $\begin{array}{l}\text { Total } \\
\text { excluding } \\
\text { adverse factors } \\
\text { listed in Table } 2\end{array}$ & $\begin{array}{l}\% \text { achieving } \\
6 / 12 \text { or better }\end{array}$ \\
\hline $\begin{array}{l}\text { Consultants } \\
\text { Surgeons in }\end{array}$ & 46 & 53 & $86 \cdot 7 \%$ \\
\hline training & 36 & 41 & $87 \cdot 8 \%$ \\
\hline Total & 82 & 94 & $87.2 \%$ \\
\hline
\end{tabular}

Table 4 All cases failing to achieve 6/12 or better

\begin{tabular}{lcc}
\hline Cause & $\begin{array}{l}\text { No. of } \\
\text { cases }\end{array}$ & $\%$ \\
\hline Pre-existing senile macular degeneration & \\
Myopic degeneration & 5 & 4.9 \\
Macular scar & 1 & $1 \cdot 0$ \\
Postoperative glaucoma ${ }^{+}$ & 1 & $1 \cdot 0$ \\
Presumed clinical cystoid macular oedema, still & 2 & $1 \cdot 9$ \\
$\quad$ present at time of writing & 5 & 4.9 \\
Postoperative hypopyon & 1 & $1 \cdot 0$ \\
Traumatic wound rupture, IOL removal, repair & 1 & $1 \cdot 0$ \\
Combined retrolental membrane and presumed & & \\
$\quad$ cystoid macular oedema & 1 & $1 \cdot 0$ \\
Retinal detachment & 1 & $1 \cdot 0$ \\
Cause uncertain & 2 & 1.9 \\
Total & 20 & $19 \cdot 6 \%$ \\
\hline
\end{tabular}

*One case combined chronic simple glaucoma and senile macular degeneration included here.

tOne case also developed shallow anterior chamber and corneal oedema.

\section{Results}

Eyes operated on by consultants numbered $56(55 \%)$ and by surgeons in training $46(45 \%)$. The type of extraction was intracapsular in 99 cases $(97 \%)$ and unplanned extracapsular in $3(2.9 \%)$. The cataracts were senile in type, and the average age of patients was 73.5 years.

\section{FINAL VISUAL ACUITIES}

Table 1 shows that without the exclusion of preexisting adverse factors $82(80 \%)$ achieved $6 / 12$ or better in the follow-up period. However, if one excludes pre-existing pathology and one case of postoperative trauma (Table 2) the percentage of cases achieving $6 / 12$ or better rises to $87 \%$. A comparison between cases operated on by consultants and those of surgeons in training can now be made (Table 3). It can be seen that both groups achieved the same results. Table 4 gives an account of the cases failing to achieve $6 / 12$ or better (where more than one cause is thought to be operating, details are given in the legend).

\section{COMPLICATIONS \\ Operative}

There were 3 eyes $(2.9 \%)$ with capsule rupture and 4 eyes with vitreous loss (3.9\%). They were managed in conventional manner and all achieved $6 / 12$ or better.

\section{Postoperative}

(a) Presumed clinical cystoid macular oedema. These were defined as eyes with (1) lowered acuity and a cystoid pattern at the macula on slit-lamp biomicroscopy and/or (2) transient lowered acuity behaving in a manner typical of cystoid macular oedema. This latter group were picked up by following serial visual acuities in the case records. In most of these an attempt was made to visualise the macula, but a cystoid pattern could not be confirmed. Fluorescein angiography was not carried out. Sixteen eyes $(15.6 \%)$ developed presumed clinical cystoid macular oedema, all except $6(5.9 \%)$ of which had recovered by the time of writing.

(b) Corneal endothelial decompensation. There were no eyes with endothelial decompensation in the 
follow-up period. One eye with glaucoma developed corneal oedema.

(c) Retinal detachment. There was one eye (1\%) which was operated on with anatomical success but achieved only hand movements acuity.

(d) Glaucoma. Transient glaucoma occurred in 13 eyes $(12.9 \%)$ and was persistent at 3 months in 14 eyes $(13.7 \%)$. Two eyes $(2 \%)$ developed narrowangle glaucoma; the rest were open-angle. Two eyes required a trabeculectomy; the rest were controlled medically.

(e) Loop dislocation. All except 4 (3.9\%) implants were sutured by their anterior upper loop to the iris. There were $9(8.8 \%)$ loop dislocations-only 1 of these was not sutured. The dislocated loops were repositioned medically in 4 cases $(3.9 \%)$ and surgically in $5(4.9 \%)$.

(f) Vitritis. The coauthors found difficulty in assessing from case records which cases had cells in vitreous when the records stated only 'vitreous haze'. An approximate incidence of vitritis in 12 eyes $(11.8 \%)$ is recorded.

(g) Hypopyon. Five eyes (4.9\%) developed a hypopyon postoperatively. This was transient in all eyes, occurring in the first few days, and was considered sterile. In all but one eye the episode did not affect the final visual acuity. Conjunctival cultures were negative. No eyes were subjected to anterior chamber or vitreous aspiration. No patients were given systemic steroids.

\section{Discussion}

The visual results ( $87 \%$ achieving $6 / 12$ or better) compare favourably with those of 2 other studies on surgeons in training of $72 \%$ in United Kingdom ${ }^{3}$ and $77 \%$ United States of America ${ }^{4}$ as well as some large studies by experienced ophthalmologists, namely: Cheng et al. ${ }^{5} 84 \%$ (Federov 1 style), ${ }^{*}$ Drews ${ }^{6} 87 \%$ (Pearce lens), ${ }^{*}$ Worst et al. ${ }^{7} 68.2 \%$ (mixed), ${ }^{*}$ Kline $^{8}$ 75-95.3\% depending on lens type, $\dagger$ Binkhorst ${ }^{9}$ $83 \%{ }^{*}$ Others reported better acuities: Roper-Hall ${ }^{10}$ $91.1 \%$ (Binkhorst 4 loop), $\dagger$ Fyoderov ${ }^{11}$ 95.2\% (Sputnik style), ${ }^{*}$ Kratz et al. ${ }^{12} 91 \cdot 2 \%$ (Shearing), ${ }^{*}$ Simcoe $^{13}$ 94\% (Simcoe), $\ddagger$ Arnott $^{14}$ 92.4\% (various posterior chamber lenses), $\ddagger$ Absolom ${ }^{15}$ 97.5\% (Choyce Mk IX), $\dagger$ Ing and Corboy ${ }^{16}$ 90\% (Choyce Mk VIII Tennant style). $\dagger$

The variation in results depends to some extent on how many cases are excluded, the' length of the follow-up period, the average age of the patients, and the reservoir they came from. Our follow-up was

\footnotetext{
${ }^{*}$ Preoperative adverse factors not excluded.

†Preoperative adverse factors excluded.

$\ddagger$ Not clear from article if exclusion or not.
}

relatively short at $6 / 12$ to 2 years (mean $12 \cdot 6$ months), and with time one would expect some of the cases with cystoid macular oedema to improve and perhaps other complications to occur. Sutton ${ }^{3}$ noted the late presentation of some of the corneal decompensations (the onset of decompensation being delayed for between 11 and 44 months in $50 \%$ of, cases.) A follow-up study of our group will reveal the incidence of these complications.

It is significant that in our study consultants and surgeons in training achieved virtually the same visual results. But it must be noted that the selection for surgery of cases to be performed by either group was not random: for example some 'high risk cases' may have been selected by the consultants. The 2 papers ${ }^{34}$ studying surgery performed by surgeons in training (quoted above) did not reveal acceptable acuities. It would seem reasonable, therefore, to propose the use of an iris clip posterior chamber lens such as the Boberg-Ans lens as a 'trainer' lens.

A high incidence of transient presumed clinical cystoid macular oedema $(15 \cdot 6 \%)$ was discovered. It may be that some of these were recorded as suspect only and could not be proved to be so. Fluorescein angiography was not employed to confirm the diagnosis. However, the number of eyes with clinically significant cystoid oedema at the time of writing is $6(5.9 \%)$. The short follow-up period is relevant in this context.

Some factors which may operate in cystoid macular oedema in the Boberg-Ans implantations are as follows. (1) There is occasionally vitreous prolapse around the side of the intraocular lens, which, it is postulated, may cause dynamic traction on the macula. Localised vitreous prolapse was observed in 16 cases $(15.7 \%)$. However, only 3 cases $(2.9 \%)$ in this group developed cystoid macular oedema. (2) The solid posterior haptic with its proximity to the ciliary body may cause an inflammatory reaction with vitritis and cystoid macular oedema on an inflammatory basis.

In reviewing 20 authors' incidence of cystoid macular oedema P. Leonard and J. Rommel ${ }^{17}$ showed a range of from $0.45 \%$ (Pearce) to $15.4 \%$ (Sheppard). They felt a $2 \%$ incidence of cystoid macular oedema was acceptable.

The absence of any corneal decompensation is encouraging, but must be stated in the light of the follow-up period (6/12 to 2 years). It was not possible to perform corneal endothelial cell counts on the patients in this study.

Loop dislocation. 8.8\% of eyes developed loop dislocation. The presence or absence of an iris suture did not appear to predispose to this complication, although we recommend suturing of all Boberg-Ans lenses. Recent figures of loop dislocations in other 
series are: Schott ${ }^{18} 2 \cdot 4 \%$, Draeger ${ }^{19} 4 \cdot 8 \%$, and Jaffe et al. ${ }^{20} 2 \cdot 8 \%$.

Hypopyon was recorded in 5 eyes $(4.9 \%)$. This was in agreement with Hunter, ${ }^{21}$ who found a $7.5 \%$ incidence when eyes were examined routinely at 48 hours on the slit-lamp. It is of interest, however, that he found $15 \%$ hypopyons when the condition was diligently sought for. Another $13 \%$ with a trace of hypopyon were found. He concluded that these were sterile and settled spontaneously without specific treatment. An exhaustive search for causative factors was fruitless. In one case in our study, although the hypopyon resolved, the acuity reached only $6 / 18$, probably because of a postinflammatory membrane.

\section{CONCLUSION}

The Boberg-Ans posterior chamber intraocular lens gives acceptable visual results in the hands of experienced surgeons and surgeons in training alike. There were no eyes with endothelial decompensation within the follow-up period. There was a higher incidence of cystoid macular oedema and loop dislocation than in other series.

Our thanks go to Mr M. J. Roper-Hall, who gave us advice and guidance in writing this paper. We also thank Pat Quinn for secretarial help. We are grateful to the consultants who allowed us to use their patients in this study.

\section{References}

1 Boberg-ans J. A new retropupillary lens with built-in glide. Clinique Ophtalmologique 1979; 4: 213-6.

2 Boberg-Ans J. Boberg-Ans posterior chamber lens. Am IntraOcular Implant Soc J 1980; 6: 380-1.

3 Sutton GA. Intraocular lens implantation by surgeons in training. Br J Ophthalmol 1980; 64: 687-8.

4 Reinhart WJ, Annable WL. Intraocular lens surgery on a residents' service. Ophthalmic Surg 1977; 8: 156-61.
5 Cheng H, Law AB, McPherson K, Price NC. Longitudinal study of intraocular implants after intracapsular cataract extraction. Complete follow up of first 7 years. Trans Ophthalmol Soc UK 1981; 101: 79-83.

6 Drews RC. The Pearce tripod posterior chamber intraocular lens-an independent analysis of Pearce's results. Am Intraocular Implant Soc J 1980; 6: 259-62.

7 Worst JGF, Mosselman CD, Ludwig HMM. The artificial lensexperience with 2000 lens implantations. Am Intra-Ocular Implant Soc J 1977; 3: 14-9.

8 Kline OR. Visual results and complications of 500 intraocular implantations. Am Intra-Ocular Implant Soc J 1978; 4: 184-91.

9 Binkhorst $C D$. Five hundred planned extracapsular extractions with iridocapsular and iris clip lens implantations in senile cataract. Ophthalmic Surg 1977; 8: 37-44.

10 Roper-Hall MJ. Intraocular lens with intracapsular cataract extraction. Trans Ophthalmol Soc UK 1981; 101: 56-7.

11 Fyoderov SN. 3000 cases of Sputnik style lens implantations. Am Intra-Ocular Implant Soc J 1980; 1: 37-9.

12 Kratz RP, Davidson B, Mazzocco TR, Colvard DM. The Shearing intraocular lens-a report on 1000 cases. Am IntraOcular Implant Soc J 1981; 7: 55-7.

13 Simcoe CW. Simcoe posterior chamber lens: theory, techniques and results. Am Intra-Ocular Implant Soc J 1981; 7: 154-7.

14 Arnott EJ. Intraocular implants. Trans Ophthalmol Soc UK 1981; 101: 58-60.

15 Absolom MJ. Experience with Choyce anterior chamber implant in the correction of aphakia. Trans Ophthalmol Soc UK 1981; 101: $69-72$.

16 Ing MR, Corboy JM. Results of 100 consecutive anterior chamber implants. Am Intra-Ocular Implant Soc J 1980; 6: 40-1.

17 Leonard P, Rommel J. Lens implantation-30 years of progress. The Hague: Junk, 1982.

18 Schott $\mathrm{K}$. Ergebnisse und erfahrungen beider Implantation intraocularer. Linson. Manuscript read before a German Ophthalmological Society meeting at Heidelberg, September 1977.

19 Draeger J. Surgical techniques-intracapsular symposium: intraocular lenses. Trans Am Ophthal Soc 1977; 81: 97-101.

20 Jaffe NS, Eichenbaum HM, Clayman HM, Light DS. A comparison of 500 Binkhorst implants with 500 routine intracapsular cataract extractions. Am J Ophthalmol 1978; 85: 24.

21 Hunter JW. Early postoperative sterile hypopyons. Br J Ophthalmol 1978; 62: 470-3. 